\title{
An Investigation of the Round Robin Brainstorming in Improving English Speaking Ability Among Nakhonphanom University's Second Year Students in Thailand
}

\author{
Raweewat Sripradith $^{1}$ \\ ${ }^{1}$ English Department, Faculty of Education, Nakhonphanom University, Thailand \\ Correspondence: Raweewat Sripradith, English Department, Faculty of Education, Nakhonphanom University, \\ Thailand. E-mail: mr.raweewat.s@gmail.com
}

Received: May 7, 2019

Accepted: May 28, 2019 Online Published: July 12, 2019

doi:10.5539/jel.v8n4p153

URL: https://doi.org/10.5539/jel.v8n4p153

\begin{abstract}
As a second-year English teacher at Nakhonphanom University, it has become important to put more emphasis on the student's ability to understand and speak the English language. The main objective as a teacher is to help the students learn the English language by utilizing the best methods. Thailand is rapidly becoming part of the global economy where university students require English speaking skills to get recognition in the global job market. As such, English teachers must double their efforts to ensure students reach international standards of communicating. Like any other university in Thailand, Nakhonphanom University has prioritized its efforts in improving the English-speaking abilities of its students. This research, therefore, aims at exploring the use of Round Robin Brainstorming as a technique to help Thai students understand and speak English through oral presentations. The researcher arranged the students in groups each having eight participants in a circular manner. Each group contained high English performing students and low English performing students. Each participant was given 5 minutes to talk about each other's weaknesses and to brainstorm ideas that would help improve these weaknesses.

The study combined both qualitative and quantitative methods. The study used a pre-test and post-test design as well as observing the students and questionnaires as data collection instruments. The overall pre-test scores showed a mean 4.03 which was low but went to a high of 11.97 in the post-test. The SD in the pre-test was 0.83 and the post-test was 0.13 meaning an overall improvement in the speaking abilities of the participants after implementing the Round Robin technique. The findings from the research showed that the pronunciation accuracy, language appropriateness, grammatical accuracies, and English fluency had been significantly higher after the implementation of the Round Robin Brainstorming technique. The students were extremely satisfied with the technique and they also felt relaxed and comfortable in discussing any of the topics given. The Round Robin Brainstorming method facilitated teamwork and enjoyment while at the same time improving the students' ability to speak English. The findings and results of this study will be used to improve the English-speaking process for Thai students. More specifically, the findings can be used as a reference while implementing the Round Robin Brainstorming technique as well as solving problems in the classrooms.
\end{abstract}

Keywords: Round Robin Brainstorming, University Student, English speaking ability

\section{Defining the Key terms}

1) Round Robin Brainstorming

According to Barkley (2014), Round Robin Brainstorming involves the generation and development of ideas in a group brainstorming session.

2) University students - they are students who have enrolled in either a college or a university. The term also refers to people who have gained admission in colleges or universities (Demirci, 2015).

3) English speaking ability is the creation of communication that contains meaning that is chosen and interprets language (Krogstad et al., 2015). They must have knowledge of the sound systems of the language and random symbols with meaning that has been agreed upon. 


\section{Background}

In recent times, English is becoming one of the most acknowledged languages for international communication. The interactions with global communities have led to the emphasis of English as the dominant language. English has become a significant asset for people looking for work in the global market and is a requirement that most employers are searching for. In order to achieve global market requirements, the need to learn and speak English has been on the rise (Methitham \& Chamcharatsri, 2011).

Being a member of the global community, Thailand has doubled its efforts in the teaching of the English language. Teaching and learning the English language in Thailand is driven by the ability of students to reach international standards of communicating. Many educational institutions in Thailand have made it a priority to teach the English language in order to meet the current market demand in the global economy (Khamkhien, 2010). In an effort to promote the English language, the Thai government has set up initiatives and strategies in educational systems that include the development of curriculums, teaching methods, and materials. Higher education systems have revised their English teaching strategies to incorporate and meet the key demands for speaking English in the job markets.

English in Thailand is taught as a second foreign or second language and as such, great efforts have been set in place to find the most appropriate teaching techniques. According to Teng and Sinwongsuwat (2015), communicating fluently in English is yet to reach the minimum standards of quality needed in the global economy. The lack of the right English curriculums and old methods of teaching such as putting emphasis on grammatical details are responsible for the deficit in quality standards. In addition, Thai English teachers lack the qualifications necessary to teach at all levels of the educational systems.

English teachers in Thailand have been employing old teaching techniques such as the Audio-lingual and translation strategies in their classrooms. This method mainly focuses on grammar and the memorization of English vocabulary as well as undertaking written exercises and translating texts. In this regard, various teaching strategies have been explored to help English students. For example, Communicative Language Teaching or (CLT) has been examined as one of the more recent teaching methods. This strategy has shown some promise as a teaching method and its effectiveness is evidenced by research performed in Western states (Methitham \& Chamcharatsri, 2011).

Another method that has been effective is the Round Robin Brainstorming technique. This is a teaching strategy involving the generation and development of ideas in a group brainstorming session. It usually involves iteration and building up of consecutive contributions from the participants which are either in verbal or written forms (Sibanda, 2015). This research, therefore, aims at exploring the use of Round Robin Brainstorming as a technique to help Thai students understand and speak English through oral presentations.

\subsection{Research Objectives}

1) To evaluate whether Round-Robin Brainstorming helps in improving the English-speaking abilities for second-year students.

2) To determine the student's attitude toward the use of brainstorming on helping them to improve their speaking ability.

\subsection{The Significance of the Research}

As the teacher for the students, the findings deduced from this study will be vital in assisting students to be better when it comes to speaking English. More specifically, the findings can be used as a reference while implementing the Round Robin Brainstorming technique as well as solving problems in the classrooms. Also, the students will be able to have a better understanding of the English language and improve their conversational skills. To the educational faculties, the study will help in the preparation of school curriculums for English lessons. The use of Round Robin Brainstorming will help the students to participate more and hence increasing their ability to learn and interact in English. The technique also provides some form of flexibility where the students will be able to adjust to new situations as they occurred. The Round Robin technique is designed to allow the participation of all students thereby encouraging teamwork and team building. This research will, therefore, help the students form better relationships with one another and help to increase confidence and satisfaction levels.

\subsection{Literature Review}

English teachers in Thailand have been employing old teaching techniques such as the Audio-lingual and translation strategies in their classrooms. This method mainly focuses on grammar and the memorization of 
English vocabulary as well as undertaking written exercises and translating texts. In this regard, various teaching strategies have been explored to help English students. For example, Communicative Language Teaching or (CLT) has been examined as one of the more recent teaching methods. This strategy has shown some promise as a teaching method and its effectiveness is evidenced by research performed in Western states (Methitham \& Chamcharatsri, 2011).

Several other methods like CLT have proven to be effective in English classrooms as they dramatically enhance the levels of speaking English. For instance, role-playing is a technique of CLT that has been used effectively to improve and enhance the speaking abilities of English students and is included in most English curriculums and textbooks. Role-playing has been an effective method that has helped students to develop their communication and conversational skills among Thai students (Tanielian, 2014). Also, English students have become more flexible and are able to adapt to new situations while making use of the English language. Due to its flexibility, students have become more relaxed while learning.

Brainstorming can enable understudies to utilize their earlier information in speech and perceive what aptitudes and data they have and what they have to know (Rao, 2007). In addition, showing understudies diverse brainstorming methods in the class is sensible in light of the fact that it may help them to develop their ability to speak and make thoughts that are vital in second language procurement (Harmer, 2001). A standout amongst the most significant highlights of brainstorming is that it needn't bother with any arrangement and it very well may be utilized at any dimension of training and under any situation.

\section{Brainstorming and EFL Learning}

There is very little literature surrounding the use of the Round Robin Brainstorming technique to help improve student teaching and learning skills. A study conducted by Susmiarti (2012) showed that the use of the Round Robin Brainstorming technique significantly improved the understanding of the English language through Classroom Action Research. Another study by Surati (2015) showed that implementing the Round Robin Brainstorming method in English classes greatly improved the speaking and conversational skills of students as well as teaching strategies. Further, the use of the technique increased the interests of students in learning and understanding the English language. The key differences between the two studies are that Susmiarti's study focused mostly on an understanding of the English language while Surati's study concentrated more on speaking.

Brainstorming and enhancement of English speaking in an EFL context are key determinants in determining the level of proficiency of students in both speech and writings. When the student gains mastery of speaking English as EFL counterparts, it elevates their level of participation in forums that requires English speaking. This study focuses more on improving the teaching strategies of English for second-year students in Thailand.

\subsection{Definition of Round Robin Brainstorming}

According to Kagan (2007), Round Robin is defined as a method in which ideas are generated and developed in brainstorming sessions. Round Robin uses an iteration process that builds on consecutive contributions from each participant either orally or verbally. Also, the technique involves teamwork effort where the participants do not question the generated ideas or ask for an explanation making it a simple and flexible tool for team building. Barkley (2012) says that Round Robin is an effective tool for generating ideas with explicit explanation and elaboration. when the participants form their ideas, the others are not allowed to question them. Each participant is therefore given a chance to express their ideas based on some given time period. Round Robin Brainstorming is a method whereby a group generates and develops ideas in a brainstorming session. it is an iterative process that builds upon consecutive contributions by each member of the group. It may either be verbal or in written form. The Round Robin method is a team effort where the members of the group generate ideas without elaborating, commenting, and explaining their ideas. One of the advantages of the Round Robin method is its simplicity and flexibility. Flexibility and ease of use make it an effective tool for enhancing team building efforts. Each team member has an opportunity to share their ideas in turns following a preset amount of time (Surati, 2015).

\subsection{Pro and Con of Brainstorming}

Susmiarti (2012) identifies the advantages of the Round Robin Brainstorming technique as there are many generated ideas that students can gather from and it helps students to explore new concepts. This means that the technique helps students to express their ideas freely without the fear of making errors. This, in turn, helps in boosting their confidence levels. Some of the weaknesses identified in other studies include: Round Robin Brainstorming is an iterative process that consumes a lot of time and problems arise especially when the number 
of students is large. Teachers find it difficult to implement the strategy in large classrooms.

\subsection{Additional Pros}

\subsubsection{Finding New Points of View}

Brainstorming gives vision and point of view where these components might not have existed previously. It supports free discourse and inventiveness, uncovering new thoughts and arrangements.

\subsubsection{Characterizing Issues}

Unconstrained reasoning in a low-weight condition can regularly characterize an issue to the point where new elective arrangements begin to show up.

\subsubsection{Equivalent Support}

Brainstorming stays away from struggle and to allow everyone to air their perspectives without prompt assessment or judgment. In a meeting to generate new ideas, everyone ought to have an equivalent chance to take an interest in the exchange. As referenced already, brainstorming should be drawn closer in the correct manner so as to be compelling.

\subsection{Additional Cons}

\subsubsection{Tedious}

The brainstorming procedure can require significant investment. It could be hours, or even days before an answer is come to.

\subsubsection{Idealistic Ideas}

Once in a while, the thoughts proposed are unworkable.

\subsubsection{Wiseacres}

Associates may decline to think about others' thoughts or outvoice others.

\subsubsection{Facilitator Required}

Brainstorming requires a pioneer or facilitator who will assume responsibility for the session and guarantee it achieves an acceptable end.

\section{Methodology}

The study combined both qualitative and quantitative methods. Quantitative method dealt with the collecting and analysis of statistical data while qualitative focused on rich data that cannot be analyzed through quantitative means. The study used a pre-test and post-test design that was crafted by the teacher on a rubric rating on scale 1 to 5 where the proficiency in speech improved from 1 heading to 5 . More so, observing the students and questionnaires were utilized. The questionnaire comprised of the general details of the respondents, the statement rating section and a section where the actual questions were explored. In the pre-test the teacher let the students choose topics from a given list that would form the basis for their discussions that would help improve their speaking abilities.

The researcher arranged the students in groups each having eight participants in a circular manner. Each group contained high English performing students and low English performing students. Each participant was given 5 minutes to talk about each other's weaknesses and to brainstorm ideas that would help improve these weaknesses. The researcher then observed the participant as they engaged in the activity and noted down their personality skills, confidence level, pronunciations, and speech content. The researcher then performed a post-test so as to make a comparison of the effects of the Round Robin Brainstorming technique. The post-test included open-ended questionnaires administered to the participants. The aim of the open-ended questionnaires was to obtain intensive opinions, feelings, emotions, and attitudes of the technique from the participants. Data analysis was coded and integrated in order to formulate conclusions.

\subsection{Data Collection}

\subsubsection{The Participants}

The participants were second-year English students at Nakhonphanom University who met the requirements of the study. the researcher used purposeful sampling technique due to the small nature of the sample as well as the use of judgment in selecting the students. The aim was to obtain a sample of students that would best represent a wide range of students perceptions and experiences after implementing the Round Robin Brainstorming method. The population sample included second-year English students with both high and low grades in the 
English-speaking course evidenced by their grades from previous semesters. The high-grade students were considered as the control group while the low-grade students were the test group. The total population of the sample was 24 students $(\mathrm{N}=24)$ comprising of 16 female students and 8 male students to maintain heterogeneity. Their ages ranged from 20 years to 25 years.

\subsection{Research Instruments}

\subsubsection{Pre-Test and Post-Test}

The Round Robin Brainstorming technique was conducted where students were given a list of topics to choose from. Each participant was given 5 minutes to make their formal presentations to the others. Both the pre-test and post-test were evaluated by the teacher and were similar in both design and procedure. The teacher then made observations of the post-test and compared the results to the pre-test with regards to English Fluency, pronunciations, grammatical accuracies, and appropriate language use. The observation form was measured on a scale of 1 to 5 where 1 = completely no knowledge, $2=$ Poor, $3=$ Satisfactory, $4=$ average, $5=$ Excellent.

\subsubsection{Questionnaires}

The questionnaires included both multiple- choice questions and open-ended questions. The multiple-choice questions were used to gather demographic information from the participants while the open-ended questions gathered the students' attitudes, emotions, feelings and opinions about the Round Robin Brainstorming technique. The following items were the basis of the teacher-evaluation form regarding the satisfaction of students after implementing Round-Robin Brainstorming: Researcher adopted the Likert rating scale, $1=$ Dissatisfied, 2 = Satisfied, 3 = Very Satisfied, 4 = Extremely Satisfied. More so, the purpose of the open-ended questions was to allow the students to give adequate pieces of information about their perceptions and satisfaction levels in their own words.

\subsection{Data Analysis}

The researcher analyzed the data based on the following research questions:

(1) Can the use of Round Robin Brainstorming help to improve the speaking ability for second-year English students?

(2) What are students' attitudes towards the use of brainstorming on helping them to enhance their speaking ability?

The participant's improvement was measured by descriptive statistics and figures were calculated into, SD, $\mathrm{t}$-Test and mean. The researcher evaluated each piece of information very keenly and made a summary of the responses of the open-ended questions to examine the participants' reactions towards the Round Robin Brainstorming technique. Summary of Data collection instruments and analysis is shown in Data Collection and Analysis Summary Table below.

Table 1. Data collection and analysis summary table

\begin{tabular}{lll}
\hline Research Questions & Data Instruments & Analysis \\
\hline $\begin{array}{ll}\text { 1) Can the use of Round Robin Brainstorming help to improve the speaking } \\
\text { ability for second-year English students? }\end{array}$ & Pre-test and post-test & t-Test, Mean, SD \\
2) What are students' attitudes towards the use of Round Robin & Questionnaires & Content analysis \\
brainstorming on helping them to enhance their speaking ability? & Open-ended questions & Narration and summary \\
\hline
\end{tabular}

\section{Findings}

Table 2. Demographic details

\begin{tabular}{llll}
\hline Participants & Male & Female & Total (Second year students) \\
\hline & 6 & 18 & 24 \\
\hline
\end{tabular}

The number of participants was 24 in which the composed of 6 males and 18 females. The results gained from the pre-test and post-test practices showed the following scores as represented in the tables. 
Table 3. Pre-test and post-test scores as adopted by Ward et al., 2018

\begin{tabular}{|c|c|c|c|c|c|c|c|}
\hline \multirow[t]{2}{*}{ Speaking Quality Measures } & \multirow[t]{2}{*}{ Total } & \multicolumn{3}{|c|}{ Pre-test } & \multicolumn{3}{|c|}{ Post-test } \\
\hline & & Mean & SD & Speaking Ability & Mean & SD & Speaking Ability \\
\hline 1) Fluency & 6 & 1.39 & 0.41 & Poor & 3.95 & 0.13 & Excellent \\
\hline 2) Pronunciation & 6 & 1.16 & 0.23 & Poor & 4.01 & 0.00 & Excellent \\
\hline 3) Language Appropriateness & 6 & 1.49 & 0.19 & Poor & 4.01 & 0.00 & Excellent \\
\hline 4) Grammatical Accuracies & 6 & 1.15 & 0.22 & Poor & 4.01 & 0.00 & Excellent \\
\hline Total & 24 & 4.03 & 0.83 & Poor & 11.97 & 0.13 & Excellent \\
\hline
\end{tabular}

Table 3 shows the pre-test and post-test scores with regards to the speaking quality aspects. The table shows that the pre-test scores given by a mean 4.03 was low but went to a high of 11.97 in the post-test. The SD in the pre-test was 0.83 and the post-test was 0.13 meaning an overall improvement in the speaking abilities of the participants after implementing the Round Robin technique.

Table 4. Paired-samples of t-test results on speaking improvement

\begin{tabular}{lllllll}
\hline Fluency test & Mean & SD & Paired Mean differences & Df & t & P-value \\
\hline Before & 1.37 & 0.41 & 2.57 & 23 & 23.20 & 0.0000 \\
After & 3.95 & 0.13 & & & & \\
\hline
\end{tabular}

Note. Significance level at 0.001 .

Table 4 shows the fluency level results of the participants after the course has greatly improved with significance level at 0.001 . this shows that the Round Robin Brainstorming technique has a positive impact on students' speaking ability.

Table 5. Pronunciation accuracy scores before and after the Round Robin Brainstorming method

\begin{tabular}{lllllll}
\hline Pronunciation Accuracy & Mean & SD & Paired Mean differences & Df & t & P-value \\
\hline Before & 1.30 & 0.47 & 2.68 & 23 & 20.19 & 0.0000 \\
After & 3.99 & 0.00 & & & & \\
\hline
\end{tabular}

Note. Significance level at 0.001 .

Table 5 shows that the participants were unable to accurately pronounce words but after the technique was implemented, they showed a significant improvement. This shows that pronunciation accuracy has improved after the implementation of the Round Robin Brainstorming technique.

Table 6. Teacher-evaluation form regarding the satisfaction of students after implementing Round-Robin Brainstorming

\begin{tabular}{|c|c|c|c|}
\hline Statement & Mean & SD & Satisfaction Levels \\
\hline 1) My ability to speak English has improved & 4.30 & 0.47 & Very satisfied \\
\hline 2) I am fluent in English & 4.30 & 0.62 & Very satisfied \\
\hline 3) Round Robin Brainstorming enabled my pronunciation & 4.45 & 0.65 & Very satisfied \\
\hline 4) Round Robin Brainstorming helps me use English appropriately & 4.22 & 0.43 & Very satisfied \\
\hline 5) Round Robin Brainstorming is enjoyable & 4.61 & 0.50 & Extremely Satisfied \\
\hline 6) Round Robin Brainstorming improves my confidence & 4.84 & 0.37 & Extremely Satisfied \\
\hline 7) Round Robin Brainstorming helps me feel relaxed and comfortable & 4.68 & 0.47 & Extremely Satisfied \\
\hline 8) Round Robin Brainstorming facilitates teamwork & 4.61 & 0.64 & Extremely Satisfied \\
\hline 9) Brainstorming helps me to reflect my grammatical error in speaking & 4.59 & 0.63 & Extremely Satisfied \\
\hline 10) Brainstorming has helped me to identify my audience and grab their attention & 4.48 & 0.62 & Very satisfied \\
\hline 11) Brainstorming has helped me to speak English better in different situations & 4.57 & 0.36 & Extremely Satisfied \\
\hline 12) Brainstorming has increased my creative thinking & 4.62 & 0.34 & Extremely Satisfied \\
\hline
\end{tabular}

Table 6 demonstrates a high general satisfaction level of the participants when the Round Robin Brainstorming method is implemented. The highest mean score of 4.84 was found to be "Round Robin Brainstorming improves my confidence". This means that the use of Round Robin Brainstorming greatly helps in boosting student's 
confidence and their interest to learn. The second highest mean was 4.68 "Round Robin Brainstorming helps me relax and comfortable". The students were extremely satisfied with the technique and they also felt relaxed and comfortable in discussing any of the topics given. The Round Robin Brainstorming method facilitated teamwork and enjoyment while at the same time improving the students' ability to speak English as evidenced by the table.

\section{Discussions}

The use of Round Robin Brainstorming helped the students to participate more and hence increasing their ability to learn and interact in English. The technique also provided some form of flexibility where the students were able to adjust to new situations as they occurred. the limitations that the studies found were that the process of implementing the Round Robin Brainstorming technique was very time consuming and expensive with regards to developing materials for class sessions (Surati, 2015). From the findings, the implementation of the Round Robin method showed an overall improvement in the speaking abilities of the participants. From Tables 3, 4 and 5 respectively, the pre-test post-test scores show a significant improvement in the fluency, language appropriateness, grammatical accuracy, and language appropriateness.

With regards to improving the teaching practices of the teachers, where the Round Robin Brainstorming method was employed, teachers were able to interact with their students more comfortably. The technique helped the students to express their ideas more freely without the fear of making mistakes. This, in turn, helped in boosting the confidence levels of the students as well as the teachers. One of the advantages of the Round Robin method is its simplicity and flexibility. Flexibility and ease of use make it an effective tool for enhancing team building efforts. Each team member had an opportunity to share their ideas in turns following a preset amount of time. One of the limitations that the researcher experienced was that Round Robin Brainstorming is an iterative process that consumes a lot of time and problems arise especially when the number of students is large. Teachers find it difficult to implement the strategy in large classrooms.

Due to the flexibility of the method, teachers and students alike were able to adapt to new situations and also enabled them to solve problems as they occurred. The essence of the Round Robin Brainstorming method was to ensure the active participation of all students in the class. As a result, their confidence levels increased due to the fact that no particular person was allowed to dominate the process. Each individual was given a chance to speak their mind hence improving their ability to learn and speak (Surati, 2015).

\section{Recommendations}

The teachers found the technique to be an effective tool for teaching since the students were able to learn more quickly. This gave the students a boost in their morale and confidence. One recommendation from this research is that teachers should incorporate this method as one of their teaching strategies that allow flexibility as well as providing a fun way to learn and speak the English language. Since the Round Robin technique is an iterative process that consumes a lot of time, the researcher recommends that it should be used on a small group of participants for it to be effective. Also, the teacher should select an appropriate period preferably during morning hours because the techniques require and involve a lot of activities and time at each particular stage. Due to the different understanding capabilities of understanding among the students, the teacher should be as clear as possible. The teacher should be able to interact with the students and where necessary they can translate some of the activities in Thai. Finally, since the study was conducted on a few numbers of students, the technique should involve every level of the educational system.

\section{References}

Barkley, E. F., Cross, K. P., \& Major, C. H. (2014). Collaborative learning techniques: A handbook for college faculty. John Wiley \& Sons.

Demirci, K., Akgönül, M., \& Akpinar, A. (2015). Relationship of smartphone use severity with sleep quality, depression, and anxiety in university students. Journal of Behavioral Addictions, 4(2), 85-92. https://doi.org/10.1556/2006.4.2015.010

Harmer, J. (2001). The practice of English language teaching (3rd ed.). Harlow: Longman.

Khamkhien, A. (2010). Teaching English Speaking and English Speaking Tests in the Thai Context: A Reflection from Thai Perspective. English Language Teaching, 3(1), 184-190.

Krogstad, J. M., Stepler, R., \& Lopez, M. H. (2015). English proficiency on the rise among Latinos.

Kumar, R. (2019). Research methodology: A step-by-step guide for beginners. Sage Publications Limited.

Methitham, P., \& Chamcharatsri, P. B. (2011). Critiquing ELT in Thailand: A reflection from history to practice. Journal of Humanities, Naresuan University, 8(2), 57-68. 
Nicholas, A. (2015). A concept-based approach to teaching speech acts in the EFL classroom. Elt Journal, 69(4), 383-394. https://doi.org/10.1093/elt/ccv034

Rukmini, D. (2010). Evaluating a Text for a Model.

Sibanda, B. (2015). Exploring Collaborative teaching strategy as a method to improve English Language Proficiency in an English Module.

Surati, S. (2015). Using Round Robin Brainstorming to Improve Students' Ability in Reading Narrative Text.

Susmiarti. (2012). Improving Students Reading Comprehension Through Round Robin Brainstorming Technique (A Classroom Action Research at the Eighth-grade students of SMP Negeril Cilongkok in Academic Year 2011/2012). Thesis.

Tanielian, A. R. (2014). Foreign language anxiety in a new English program in Thailand. International Education Journal: Comparative Perspectives, 13(1), 60-81.

Teng, B., \& Sinwongsuwat, K. (2015). Teaching and Learning English in Thailand and the Integration of Conversation Analysis (CA) into the Classroom. English Language Teaching, 8(3), 13-23. https://doi.org/10.5539/elt.v8n3p13

\section{Copyrights}

Copyright for this article is retained by the author, with first publication rights granted to the journal.

This is an open-access article distributed under the terms and conditions of the Creative Commons Attribution license (http://creativecommons.org/licenses/by/4.0/). 